University of Wollongong

Research Online

Australian Institute for Innovative Materials -

Papers

Australian Institute for Innovative Materials

$1-1-2018$

\title{
Homogeneous Sulfur-Cobalt Sulfide Nanocomposites as Lithium-Sulfur Battery Cathodes with Enhanced Reaction Kinetics
}

Mengmeng Lao

University of Wollongong, ml590@uowmail.edu.au

Guoqiang Zhao

University of Wollongong, gz815@uowmail.edu.au

Xin Li

University of Wollongong, xl14@uow.edu.au

Yaping Chen

University of Wollongong, yc463@uowmail.edu.au

Shi Xue Dou

University of Wollongong, shi@uow.edu.au

See next page for additional authors

Follow this and additional works at: https://ro.uow.edu.au/aiimpapers

Part of the Engineering Commons, and the Physical Sciences and Mathematics Commons

Research Online is the open access institutional repository for the University of Wollongong. For further information contact the UOW Library: research-pubs@uow.edu.au 


\title{
Homogeneous Sulfur-Cobalt Sulfide Nanocomposites as Lithium-Sulfur Battery Cathodes with Enhanced Reaction Kinetics
}

\author{
Abstract \\ Lithium sulfur (Li-S) batteries, as promising alternatives to lithium ion batteries (LIBs), are drawing \\ significant attention owing to their high theoretical capacity and energy density. However, the sluggish \\ reaction kinetics and poor cycling stability have remained a great challenge, hindering the practical \\ application of Li-S batteries. Herein, sulfur-cobalt sulfide nanocomposites with tunable sulfur content \\ were synthesized via a facile one-pot refluxing method towards enhanced reaction kinetics for $\mathrm{Li}-\mathrm{S}$ \\ batteries. Uniform distribution of sulfur and cobalt sulfide at the nanoscale was achieved in the \\ composites. The sulfur-cobalt sulfide nanocomposites delivered higher specific capacities and \\ significantly enhanced rate performance compared to bulk sulfur cathode. The significant performance \\ improvement is in great part due to the formation of sulfur nanoparticles and greatly improved electrical \\ conductivity of the nanocomposites, which would result in shortened mass diffusion pathway and \\ enhanced charge-transfer ability, thereby inducing accelerated electrode reaction kinetics.

\section{Disciplines} \\ Engineering | Physical Sciences and Mathematics

\section{Publication Details} \\ Lao, M., Zhao, G., Li, X., Chen, Y., Dou, S. \& Sun, W. (2018). Homogeneous Sulfur-Cobalt Sulfide \\ Nanocomposites as Lithium-Sulfur Battery Cathodes with Enhanced Reaction Kinetics. ACS Applied \\ Energy Materials, 1 (1), 167-172.

\section{Authors} \\ Mengmeng Lao, Guoqiang Zhao, Xin Li, Yaping Chen, Shi Xue Dou, and Wenping Sun
}




\title{
Homogeneous Sulfur-Cobalt Sulfide
}

\section{Nanocomposites as Lithium-Sulfur Battery Cathodes with Enhanced Reaction Kinetics}

\author{
Mengmeng Lao, Guoqiang Zhao, Xin Li, Yaping Chen, Shi Xue Dou, Wenping Sun* \\ Institute for Superconducting and Electronic Materials, Australian Institute of Innovative \\ Materials, University of Wollongong, Wollongong, NSW 2522, Australia
}

\begin{abstract}
Lithium sulfur (Li-S) batteries, as promising alternatives to lithium ion batteries (LIBs), are drawing significant attention owning to their high theoretical capacity and energy density. However, the sluggish reaction kinetics and poor cycling stability have been remaining a great challenge, hindering the practical application of Li-S batteries. Herein, sulfur-cobalt sulfide nanocomposites with tunable sulfur content were synthesized via a facile one-pot refluxing method towards enhanced reaction kinetics for Li-S batteries. Uniform distribution of sulfur and cobalt sulfide in nanoscale was achieved in the composites. The sulfur-sulfide nanocomposites delivered higher specific capacities and significantly enhanced rate performance compared to bulk sulfur cathode. The significant performance improvement is in great part due to the formation of sulfur nanoparticles and greatly improved electrical conductivity of the nanocomposites, which would result in shortened mass diffusion pathway and enhanced charge transfer ability, thereby inducing accelerated electrode reaction kinetics.
\end{abstract}


KEYWORDS: cobalt sulfide, nanocomposite, reaction kinetics, cathode, lithium-sulfur batteries

\section{INTRODUCTION}

The unsatisfactory energy density $\left(\sim 250 \mathrm{~W} \mathrm{~h} \mathrm{~kg}^{-1}\right)$ and in particular high cost of LIBs can hardly sustain the commercial viability of electrified transportation and grid energy storage as well. And the ever-growing demand for low cost, long cycling life and high energy density rechargeable batteries, which are sustainably desired by portable electronic devices, electrical vehicles (EVs) and large-scale energy storage, has driven the prosperous development of new battery systems. Among the alternatives to LIBs, Li-S batteries exhibit significant superiority because the reaction mechanism of sulfur $\left(\mathrm{S}_{8}\right) \mathrm{vs} . \mathrm{Li} / \mathrm{Li}^{+}$is totally different from those conventional intercalation cathode materials (e.g., $\mathrm{LiCoO}_{2}, \mathrm{LiFePO}_{4}$ ). $\mathrm{S}_{8}$ reacts with lithium via conversion reaction accompanied with the formation of lithium sulfide, which endows $\mathrm{S}_{8}$ with an ultrahigh theoretical capacity of $1675 \mathrm{~mA} \mathrm{~h} \mathrm{~g}^{-1}$ and a corresponding energy density of $2500 \mathrm{Wh}$ $\mathrm{kg}^{-1}$. ${ }^{1}$ This affords Li-S batteries 5 times higher energy density than that of LIBs. Besides, sulfur shares the advantages of earth abundance, by-product of the petroleum refining process and environmental friendliness, which ensure Li-S batteries to be a low-cost battery system. However, tremendous challenges for the sulfur cathode remain to be addressed. First, both sulfur and lithium sulfide is insulator, resulting in sluggish reaction kinetics without incorporating a great proportion of conductive additives and/or decreasing particle size of sulfur. Besides, the corresponding lithiation/delithiation reaction is accompanied by a huge volume change (formation of $\mathrm{Li}_{2} \mathrm{~S}$ leads to $80 \%$ volume expansion compared to sulfur). Moreover, the intermediate long-chain lithium polysulfides (LiPSs) (e.g., $\mathrm{Li}_{2} \mathrm{~S}_{8}, \mathrm{Li}_{2} \mathrm{~S}_{6}$ ) are soluble in the liquid electrolytes and would shuttle between cathode and anode through electrolyte over cycling 
(shuttle effect), resulting in the loss of active material and the passivation/deterioration of metal lithium anode as well as the formation of unstable solid-state interphase (SEI) ${ }^{2-3}$ These problems would lead to poor rate performance, fast capacity decay and low Coulombic efficiency of the Li-S batteries.

In order to addressing the challenges associated with sulfur cathode, various approaches have been developed over the past years. Combining sulfur with conductive carbonaceous scaffolds is most extensively investigated, which can not only physically trap the intermediate LiPSs, mitigate shuttle effect, but also facilitate charge transfer. ${ }^{4-11}$ However, the nonpolar carbon hosts are not very efficient in adsorbing polar LiPSs. Compounds combining functional polar groups such as metal sulfides (e.g., $\mathrm{CoS}_{2},{ }^{12} \mathrm{TiS}_{2}$ ) and metal oxides (e.g., TiO, ${ }^{13-14} \mathrm{TiO}_{2},{ }^{15}$ $\mathrm{MgO},{ }^{16} \mathrm{MnO}_{2}{ }^{17}$ ) were demonstrated to be efficient to adsorb LiPSs. Besides, sulfur-polymer composites, where polymers may work as a conductive matrix and/or barrier for suppressing shuttle effect were also widely studied. ${ }^{18-20}$ The application of interlayers between the cathode and separator has also been developed as effective polysulfides (PSs) encapsulating methods. ${ }^{21-24}$ Moreover, reducing the particle size of the sulfur cathode is on the other side an approach to circumvent the related issues, as nanomaterials help to improve the conductivity by shortening electron conduction path and alleviate the volume change effect by providing surface relaxation space. ${ }^{25-26}$ In addition, studies focused on facilitating redox kinetics such as incorporating polar mediators into sulfur were also reported intensively. ${ }^{12-13,27-29}$

Herein, a facile one-pot refluxing method was developed to synthesize sulfur-cobalt sulfide nanocomposites as cathodes for Li-S batteries. In addition to obtain sulfur nanoparticles, the uniform incorporation of cobalt sulfide $\left(\mathrm{CoS}_{2}\right.$ and $\left.\mathrm{Co}_{9} \mathrm{~S}_{8}\right)$ nanoparticles would also help to substantially improve the electrical conductivity of the nanocomposites because of the superior 
conductive behaviour of cobalt sulfides. ${ }^{30-33}$ Benefiting from the unique characteristics, the nanocomposites are anticipated to deliver significantly enhanced electrode reaction kinetics, including accelerating the redox reaction of LiPSs, promoting nucleation of $\mathrm{Li}_{2} \mathrm{~S}_{2} / \mathrm{Li}_{2} \mathrm{~S}$, and facilitating Li ion transport and charge transfer process. ${ }^{12}$

\section{EXPERIMENTAL SECTION}

Synthesis of sulfur-cobalt sulfide nanocomposites. A facile refluxing method was utilized to synthesis sulfur-cobalt sulfide nanocomposites. For example, $1.6 \mathrm{mmol}$ cobalt (II) chloride (Sigma-Aldrich, 97\%), $12.8 \mathrm{mmol}$ 1, 3, 4-thiadiazole-2, 5-dithiol (DMCT) (Sigma-Aldrich, 98\%) and $40 \mathrm{~mL}$ ethylene glycol (Sigma-Aldrich, 99.8\%) were mixed in a three neck round bottom flask with magnetic stirring to form a homogeneous suspension. In the meanwhile, high pure argon flow was introduced to purge air out of the flask for 20 minutes before heating. Then, the suspension was quickly heated to $160{ }^{\circ} \mathrm{C}$ under magnetic stirring and argon protection utilizing a stirring heating mantle, which was held for 2-hour dwell time. The product was finally collected via centrifugation method, and then the wet product was dried in vacuum oven at $60{ }^{\circ} \mathrm{C}$ overnight. Brown powder was collected after drying, which is donated as $\mathrm{S}-\mathrm{CoS}_{\mathrm{x}}-8$.

Characterization of materials. The morphology and microstructure of $\mathrm{S}-\mathrm{CoS}_{\mathrm{x}}-8, \mathrm{~S}-\mathrm{CoS}_{\mathrm{x}}-4$ nanocomposites were characterized using JEOL JSM-7500 scanning electron microscopy (SEM) and JEOL JEM-2010 transmission electron microscopy (TEM). The phase structure was measured by X-ray diffraction (XRD) (GBC MMA, Australia). X-ray photoelectron spectroscopy (XPS) measurements were conducted by Thermo VG ESCALAB 250 spectrometer using $\mathrm{Al} \mathrm{K} \alpha$ radiation $(1486.6 \mathrm{eV})$. Scanning transmission electron microscopy 
(STEM) characterization was conducted utilizing the probe-corrected JEOL ARM-200F equipment.

Electrochemical measurements. Electrolyte was prepared by dissolving $1 \mathrm{M}$ lithium bis(trifluoromethanesulfonyl)imide and 0.1 M lithium nitrate additive in 1,2-dimethoxyethane and 1,3-dioxolane $(1: 1 \mathrm{vol} \%)$ mixed solvent. Electrodes were prepared as the following traditional method: The $\mathrm{S}-\mathrm{CoS}_{\mathrm{x}}$ powders, carbon nanotubes and poly(vinyl difluoride) were mixed in $\mathrm{N}$-methylpyrrolidone with the mass ratio of $8: 1: 1$, which was then formed into homogeneous slurry via mortar milling. The slurry was subsequently coated on aluminium foils followed by $60{ }^{\circ} \mathrm{C}$ vacuum oven drying overnight. The as-prepared electrode film was cut into $9.5 \mathrm{~mm}$-diameter discs, and the average mass loading of active material was $2 \mathrm{mg} \mathrm{cm}^{-2}$. As a comparison, the commercial sulfur powders were also applied to prepared electrodes using the same method as mentioned above. And the average mass loading of bulk $\mathrm{S}$ was $2 \mathrm{mg} \mathrm{cm}{ }^{-2}$. The LIR 2032-type coin cells were assembled in an argon-filled glove box with both water and oxygen concentrations less than $1 \mathrm{ppm}$. $\mathrm{CV}$ test was conducted at the scan rate of $0.1 \mathrm{mV} \mathrm{s}^{-1}$ in the voltage range from 1.7 to $2.8 \mathrm{~V}$ using a Solartron electrochemical workstation. The Galvanostatic charge-discharge test was carried out at various current densities over the voltage range from 1.7 to $2.8 \mathrm{~V}$ utilizing a battery test system (LAND CT2001A). EIS measurements were performed via Solartron electrochemical workstation in the frequency range from $100 \mathrm{kHz}$ to $10 \mathrm{mHz}$.

\section{RESULTS AND DISCUSSION}

Figure 1a shows the XRD patterns of the as-prepared samples synthesized with different molar ratio of $\mathrm{CoCl}_{2}$ and DMCT, where $\mathrm{CoCl}_{2}$ : DMCT $=1: 8$ and 1:4 are denoted as $\mathrm{S}-\mathrm{CoS}_{\mathrm{x}}-8$ and 
S-CoS -4 , respectively. Most of the diffraction peaks of both samples could be readily indexed to the standard orthorhombic sulfur (JCPDS No. 08-0247). Only a few peaks corresponding to cobalt sulfides patterns are present probably because the peaks are overlapped with those of $S$ or the cobalt sulfides are poorly crystallized. The peaks at $2 \theta=27.7,32.2$ and $36^{\circ}$ can be assigned to $\mathrm{CoS}_{2}$ (JCPDS No. 41-1471), corresponding to the planes of (111), (200) and (210), respectively. And the diffraction peaks at $2 \theta=25.2$ and $31.2^{\circ}$ can be indexed to $\mathrm{Co}_{9} \mathrm{~S}_{8}$ (JCPDS No. 02-1459). The commercial bulk sulfur powders also show orthorhombic phase structure (JCPDS No. 080247), as presented in Figure S1 (Supporting Information). SEM and TEM were conducted to examine the morphology. As seen from Figure $1 \mathrm{~b}$ and $\mathrm{c}$, the $\mathrm{S}-\mathrm{CoS}_{\mathrm{x}}-8$ nanocomposite consists of nanoparticles with smooth surface and diameter ranging from 200 to $300 \mathrm{~nm}$. S-CoS -4 also presents similar particle morphology (Figure S2c-d and Figure S3a, Supporting Information), while commercial sulfur powder exhibits bulk and disordered particle distribution (Figure S2a and $b$, Supporting Information). In the high resolution TEM (HRTEM) image of $\mathrm{S}-\mathrm{CoS}_{\mathrm{x}}-8$ (Figure 1d), the lattice spacing of 0.25 and $0.3 \mathrm{~nm}$ corresponds to the (210) plane of $\mathrm{CoS}_{2}$ and the (311) plane of $\mathrm{Co}_{9} \mathrm{~S}_{8}$, respectively. The selected area electron diffraction pattern (SAED) (insert of Figure 1d) shows similar results to that of HRTEM analysis. Moreover, Figure S3b-c (Supporting Information) display HRTEM images of $\mathrm{S}-\mathrm{CoS}_{\mathrm{x}}-4$ nanocomposite. The lattice spacing of 0.25 and $0.275 \mathrm{~nm}$ can be assigned to the (210) and (200) planes of $\mathrm{CoS}_{2}$, respectively, and the lattice spacing of $0.2 \mathrm{~nm}$ can be indexed to the (220) planes of $\mathrm{Co}_{9} \mathrm{~S}_{8}$. All the HRTEM results confirm the formation of cobalt sulfide nanograins, which is in accordance with XRD results. Furthermore, the corresponding STEM elemental mappings demonstrate the distribution of Co and S, as shown in Figure 1e-g. One can clearly see that uniform distribution of $\mathrm{Co}$ and $\mathrm{S}$ is achieved in the nanocomposite. Besides, the as-prepared nanocomposites (Figure 
S4, Supporting Information) turn to be brown from yellow for sulfur, which can be ascribed to the incorporation of black cobalt sulfides. This also proves the formation of sulfur-cobalt sulfide nanocomposite. Also, the colour of $\mathrm{S}-\mathrm{CoS}_{\mathrm{x}}-4$ is a bit darker than that of $\mathrm{S}-\mathrm{CoS}_{\mathrm{x}}-8$ in great part due to the higher proportion of cobalt sulfides. All the results suggest the successful preparation of sulfur-cobalt sulfide nanocomposites via the facile refluxing approach.

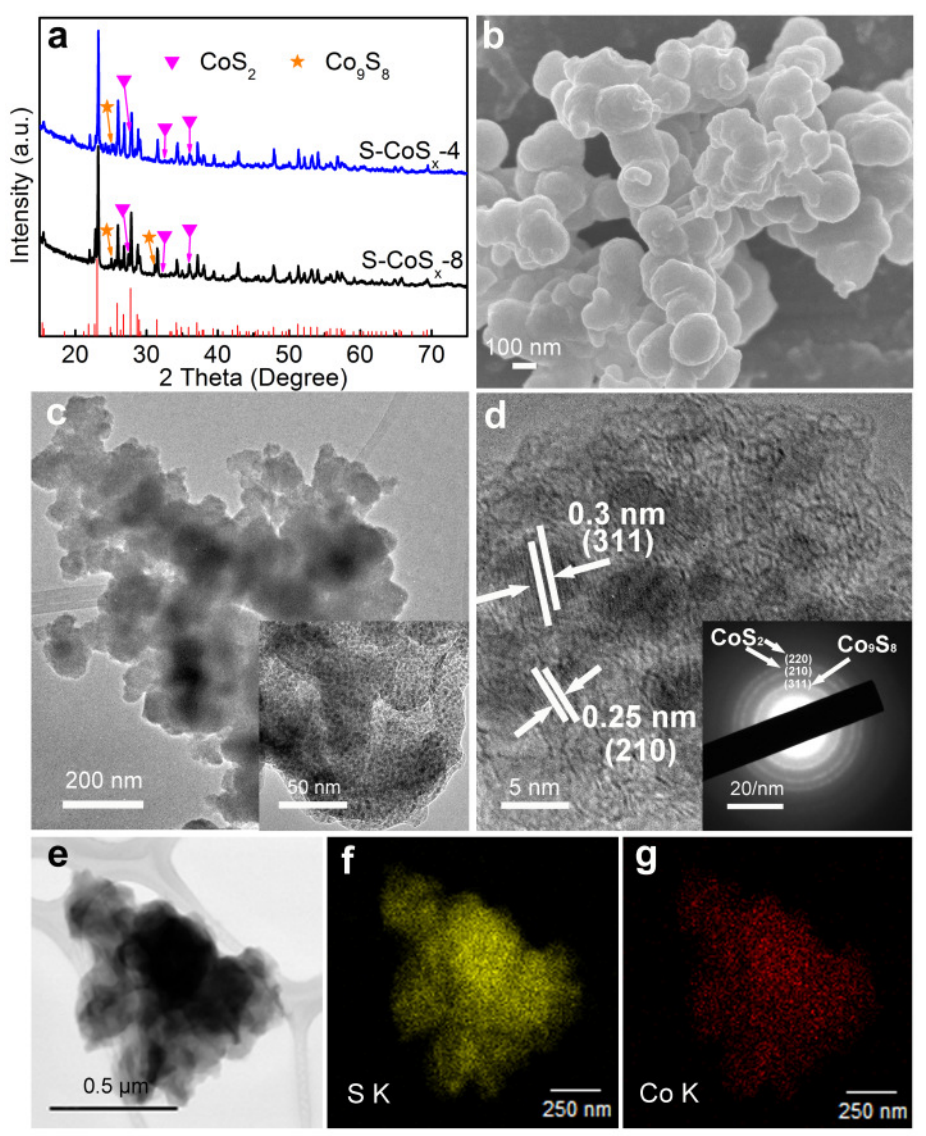

Figure 1. (a) XRD patterns, (b) SEM image, (c) Low-magnification and high-magnification (insert) TEM images, (d) HRTEM image and SAED pattern (insert), (e-g) STEM image and the corresponding $\mathrm{S}$ and Co elemental mapping images of $\mathrm{S}-\mathrm{CoS}_{\mathrm{x}}-8$ nanocomposite. 
To further verify the chemical composition of the sulfur-cobalt sulfide nanocomposites, XPS analysis was carried out. Figure 2a demonstrates the high-resolution XPS spectrum of $\mathrm{S} 2 \mathrm{p}$ for $\mathrm{S}$ $\mathrm{CoS}_{\mathrm{x}}-8$ nanocomposite, the spectra shows one binding environment $\left(\mathrm{E}_{\mathrm{b}}<166 \mathrm{eV}\right)$ consisting of three components. The peak at $164 \mathrm{eV}$ can be assigned to pure $\mathrm{S}\left(31.4\right.$ at\%), ${ }^{6,13,34}$ and the peak at $161.3 \mathrm{eV}$ corresponds to $\mathrm{S}_{2}{ }^{2-}(18.2 \mathrm{at} \%) .{ }^{35-36}$ The most intensive peak at $162.8 \mathrm{eV}$ could be ascribed to $\mathrm{S}_{6}{ }^{2-}(50.4$ at $\%)$ according to previous report ${ }^{37}$. Figure $2 \mathrm{~b}$ depicts the high-resolution Co $2 p$ XPS spectrum which consists of two spin-orbit doublets and two shakeup satellites (donated as "Sat."). The two spin-orbit doublets could be assigned to Co $2 \mathrm{p}_{3 / 2}\left(\mathrm{E}_{\mathrm{b}}<785 \mathrm{eV}\right)$ and Co $2 \mathrm{p}_{1 / 2}\left(\mathrm{E}_{\mathrm{b}}>790 \mathrm{eV}\right)$, respectively. The peaks located at 778.7 and $793.8 \mathrm{eV}$ corresponds to $\mathrm{Co}^{3+}$, while another two peaks at 780 and $795.5 \mathrm{eV}$ are attributed to $\mathrm{Co}^{2+} \cdot{ }^{38-42}$ The spin-orbit splitting between Co $2 \mathrm{p}_{3 / 2}$ and Co $2 \mathrm{p}_{1 / 2}$ is determined to be $15 \mathrm{eV}$, which is in accordance with the previous report with respect to the existence of Co-S bond. ${ }^{43}$ Furthermore, the molar ratio of $\mathrm{S}$ to Co for $\mathrm{S}-\mathrm{CoS}_{\mathrm{x}}-8$ is determined to be 7 based on XPS and energy-dispersive X-ray spectroscopy (EDS) analysis (Figure S5, Supporting Information). XPS and EDS analysis results for $\mathrm{S}-\mathrm{CoS}_{\mathrm{x}}-4$ are also shown in Figure S6 (Supporting Information). $\mathrm{S}_{2}{ }^{2-}\left(42.4\right.$ at\%) and $\mathrm{S}_{8}(33.4$ at $\%$ ) peaks could also be fitted in the XPS spectra of S-CoS $-4,6,17,34$ and $\mathrm{S}_{4}{ }^{2-}$ (24.2 at\%) can be fitted according to the previous report. ${ }^{44}$ The molar ratio of sulfur to cobalt is estimated to 6 for S-CoS $\mathrm{S}_{\mathrm{x}}-4$ based on the EDS analysis, which is lower than that of $\mathrm{S}-\mathrm{CoS}_{\mathrm{x}}-8$. Noticeably, the proportion of $\mathrm{S}_{2}^{2-}$ species in $\mathrm{S}-\mathrm{CoS}_{\mathrm{x}}-4$ is higher than that in $\mathrm{S}-\mathrm{CoS}_{\mathrm{x}}-8$ according to the fitted XPS profiles, which is in agreement with the results discussed in Figure S4 that the colour of S-CoS $\mathrm{x}^{-}$ 4 is darker than that of $\mathrm{S}-\mathrm{CoS}_{\mathrm{x}}-8$. And the higher proportion of $\mathrm{CoS}_{2}$ in $\mathrm{S}-\mathrm{CoS}_{\mathrm{x}}-4$ might induce lower practical capacity as compared to $S-\operatorname{CoS}_{\mathrm{x}}-8$, which will be discussed in the following section. 

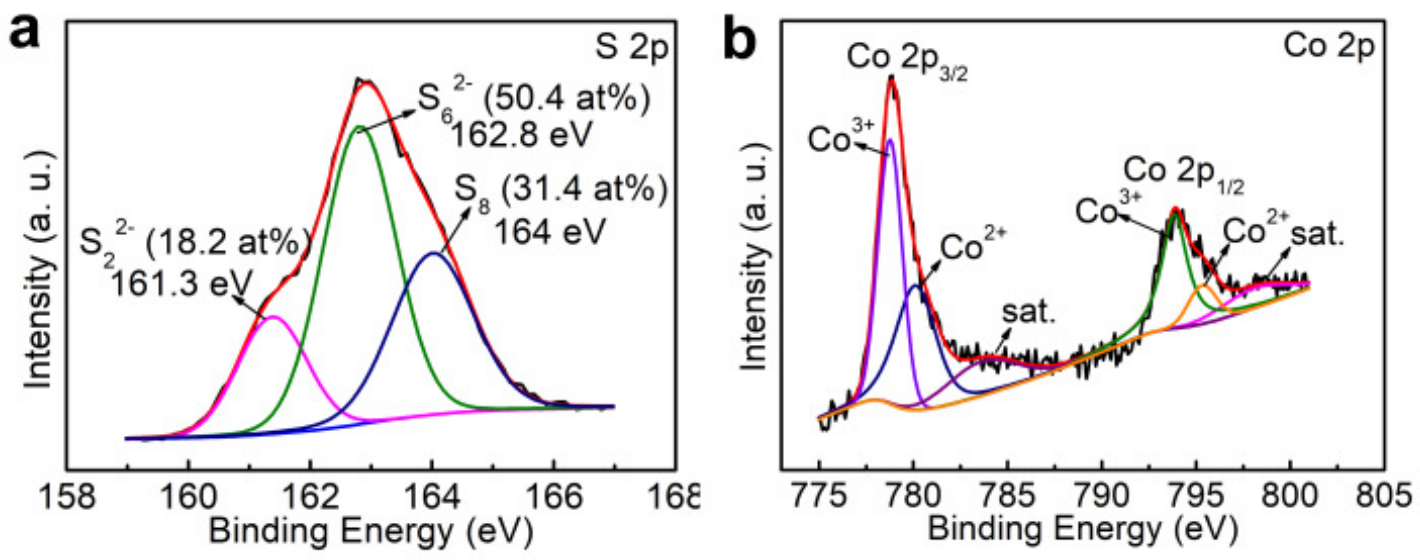

Figure 2. High-resolution XPS spectrum of $S-\mathrm{CoS}_{\mathrm{x}}-8$ nanocomposite: (a) $\mathrm{S} 2 \mathrm{p}$ and (b) Co 2p.

The electrochemical performances of S-CoS $-8, S-\operatorname{CoS}_{x}-4$ and bulk $\mathrm{S}$ were tested in etherbased electrolyte with similar areal mass loading of $\sim 2 \mathrm{mg} \mathrm{cm}^{-2}$. Figure $3 \mathrm{a}$ and $\mathrm{b}$ present the galvanostatic charge-discharge profiles of $\mathrm{S}-\mathrm{CoS}_{\mathrm{x}}-8$ nanocomposite and bulk $\mathrm{S}$ at the current density of $100 \mathrm{~mA} \mathrm{~g}^{-1}$ in the potential range from 1.7 to $2.8 \mathrm{~V}$. The discharge curves consist of two typical plateaus at 2.3 and $2.1 \mathrm{~V}$, which corresponds to the reduction reaction from sulfur (S$\mathrm{CoS}_{\mathrm{x}}$ nanocomposites) to $\mathrm{Li}_{2} \mathrm{~S}_{4}$ and the reduction reaction from $\mathrm{Li}_{2} \mathrm{~S}_{4}$ to $\mathrm{Li}_{2} \mathrm{~S}$, respectively. During the charge process, the two plateaus represent the backward reaction from $\mathrm{Li}_{2} \mathrm{~S} / \mathrm{Li}_{2} \mathrm{~S}_{2}$ to LiPSs. ${ }^{37}$ The charge-discharge curves of $\mathrm{S}-\mathrm{CoS}_{\mathrm{x}}-8$ nanocomposite are in good agreement with the redox process established in the typical cyclic voltammetry (CV) curves as shown in Figure 3c. In contrast, the charge-discharge curves of bulk $\mathrm{S}$ are not in accordance with its CV profiles as shown in Figure $3 \mathrm{~b}$ and d, where the reduction peak at $2.0 \mathrm{~V}$ is considerably weaker than that at $2.2 \mathrm{~V}$ in $\mathrm{CV}$ profiles, which might be ascribed to the sluggish reaction kinetics. ${ }^{45-46}$ Besides, $\mathrm{S}$ $\mathrm{CoS}_{\mathrm{x}}-8, \mathrm{~S}-\mathrm{CoS}_{\mathrm{x}}-4$ (Figure S7a, Supporting Information) and bulk S delivers reversible specific capacity of 838,759 , and $633 \mathrm{~mA} \mathrm{~h} \mathrm{~g}^{-1}$ at $100 \mathrm{~mA} \mathrm{~g}^{-1}$, respectively. Clearly, the nanocomposites exhibit superior specific capacity over bulk $\mathrm{S}$. The theoretical capacities for $\mathrm{S}-\mathrm{CoS}_{\mathrm{x}}-8$ and $\mathrm{S}-$ 
$\mathrm{CoS}_{\mathrm{x}}-4$ are calculated based on the nominal chemical composition of $\mathrm{CoS}_{7}$ and $\operatorname{CoS}_{6}$ (Figure S5S6, Supporting Information), assuming they are reduced to nominal $\mathrm{CoS}_{2}$ during the discharge process because the reported discharge plateaus of $\mathrm{CoS}_{2}$ in LIBs is lower than $1.7 \mathrm{~V},{ }^{47-48}$ and the calculated theoretical capacities for cobalt polysulfides are depicted in Figure S8 (Supporting Information). S- $\mathrm{CoS}_{\mathrm{x}}-8, \mathrm{~S}-\mathrm{CoS}_{\mathrm{x}}-4$, and $\mathrm{S}$ possesses theoretical capacity of $945,852.8$, and 1675 $\mathrm{mA} \mathrm{h} \mathrm{g}{ }^{-1}$, respectively, and correspondingly the capacity utilization is determined to be $88.7 \%$, $89 \%$, and $37.8 \%$. Moreover, the voltage profiles indicate that the polarization of $\mathrm{S}-\mathrm{CoS}_{\mathrm{x}}-8(174$ $\mathrm{mV})$ and S-CoS $\mathrm{x}_{\mathrm{x}}-4(208 \mathrm{mV})$ (Figure S7a, Supporting Information) is much smaller than that of bulk $\mathrm{S}(244 \mathrm{mV})$, suggesting faster redox kinetics and higher energy efficiency of $\mathrm{S}-\mathrm{CoS}_{\mathrm{x}}-8$ and S-CoS $\mathrm{x}_{\mathrm{x}}-4$ nanocomposites.
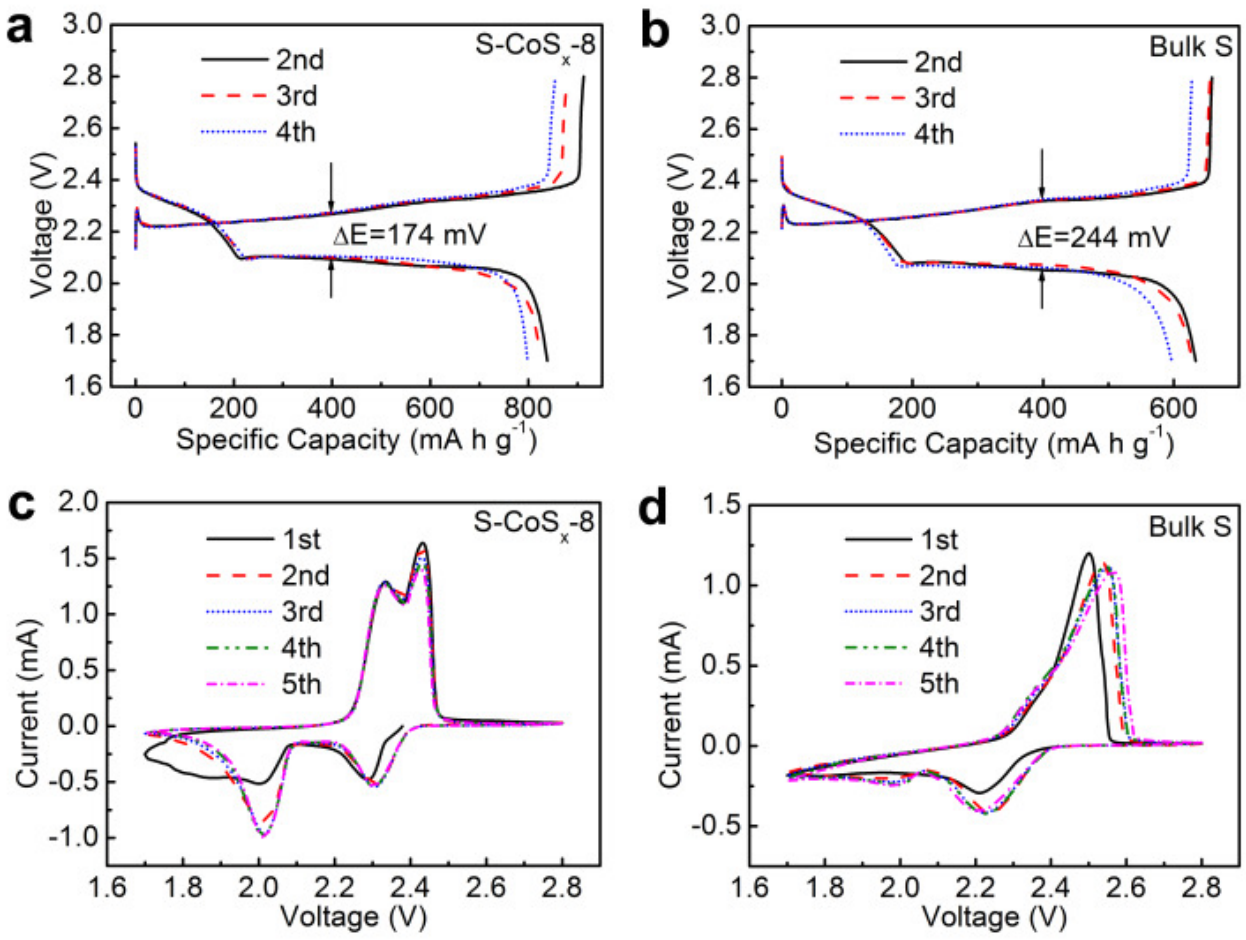

Figure 3. Charge-discharge curves of (a) $\mathrm{S}-\mathrm{CoS}_{\mathrm{x}}-8$ nanocomposite and (b) bulk $\mathrm{S}$ at $100 \mathrm{~mA} \mathrm{~g}^{-1}$, CV curves of (c) S-CoS $\mathrm{x}_{\mathrm{x}}-8$ nanocomposite and (d) bulk $\mathrm{S}$ at the scan rate of $0.1 \mathrm{mV} \mathrm{s}^{-1}$. 
To evaluate the rate capability, S-CoS $-8, S-C_{x} S_{x}-4$ and bulk $S$ cathodes were cycled at various current densities from 0.1 to $2 \mathrm{~A} \mathrm{~g}^{-1}$. As shown in Figure 4a, bulk S exhibits discharge capacity of 598, 560.9, 486.7, 335.7 and $144.5 \mathrm{~mA} \mathrm{~h} \mathrm{~g}^{-1}$ at $0.2,0.3,0.5,1$ and $2 \mathrm{~A} \mathrm{~g}^{-1}$, respectively. In contrast, $\mathrm{S}-\mathrm{CoS}_{\mathrm{x}}-8$ delivers the capacities of $775.8,729,688,645$ and $525.2 \mathrm{~mA}$ $\mathrm{h} \mathrm{g}^{-1}$, respectively. S-CoS $\mathrm{x}_{\mathrm{x}}-4$ also shows very promising specific capacity at various current densities. The results reveal that the rate capability is significantly improved for sulfur-cobalt sulfide nanocomposite as compared with bulk S. Due to the different theoretical capacities of the cathodes, the practical C-rate performance is varied for each sample. For instance, at the current density of $2 \mathrm{~A} \mathrm{~g} \mathrm{~g}^{-1}$, the practical C-rate is $1.19,1.76$ and $2.05 \mathrm{C}$ for S, S-CoS -8 and $\mathrm{S}-\mathrm{CoS}_{\mathrm{x}}-4$, respectively. As can be seen from Figure $4 b, S-C o S_{x}-8$ and $S-C o S_{x}-4$ exhibit greatly improved capacity utilization over bulk S, owing to the fast reaction kinetics and better electrode stability at high rate. Among the three samples, $\mathrm{S}-\mathrm{CoS}_{\mathrm{x}}-8$ eventually shows the highest specific capacity with good rate capability, which could benefit from the relatively higher theoretical capacity $\left(945 \mathrm{~mA} \mathrm{~h} \mathrm{~g}^{-1}\right)$ and fast electrode reaction kinetics. Furthermore, charge-discharge curves of S$\mathrm{CoS}_{\mathrm{x}}-8$ and bulk $\mathrm{S}$ at different current densities from 0.2 to $1 \mathrm{~A} \mathrm{~g}^{-1}$ are presented in Figure $4 \mathrm{c}$ and d. It is obvious that $\mathrm{S}-\mathrm{CoS}_{\mathrm{x}}-8$ exhibits low polarization with voltage gaps of 185, 222, 273 and $367 \mathrm{mV}$, respectively, at $0.2,0.3,0.5$ and $1 \mathrm{~A} \mathrm{~g} \mathrm{~g}^{-1}$, while bulk $\mathrm{S}$ delivers considerably higher polarization than that of $S-\mathrm{CoS}_{\mathrm{x}}-8$. The typical two plateaus in the charge-discharge curves for S$\mathrm{CoS}_{\mathrm{x}}-8$ are maintained very well at various current densities, and the second discharge plateau is still higher than $2.0 \mathrm{~V}$ even at high rate, further confirming the excellent rete performance of S$\mathrm{CoS}_{\mathrm{x}}-8$ nanocomposite. 

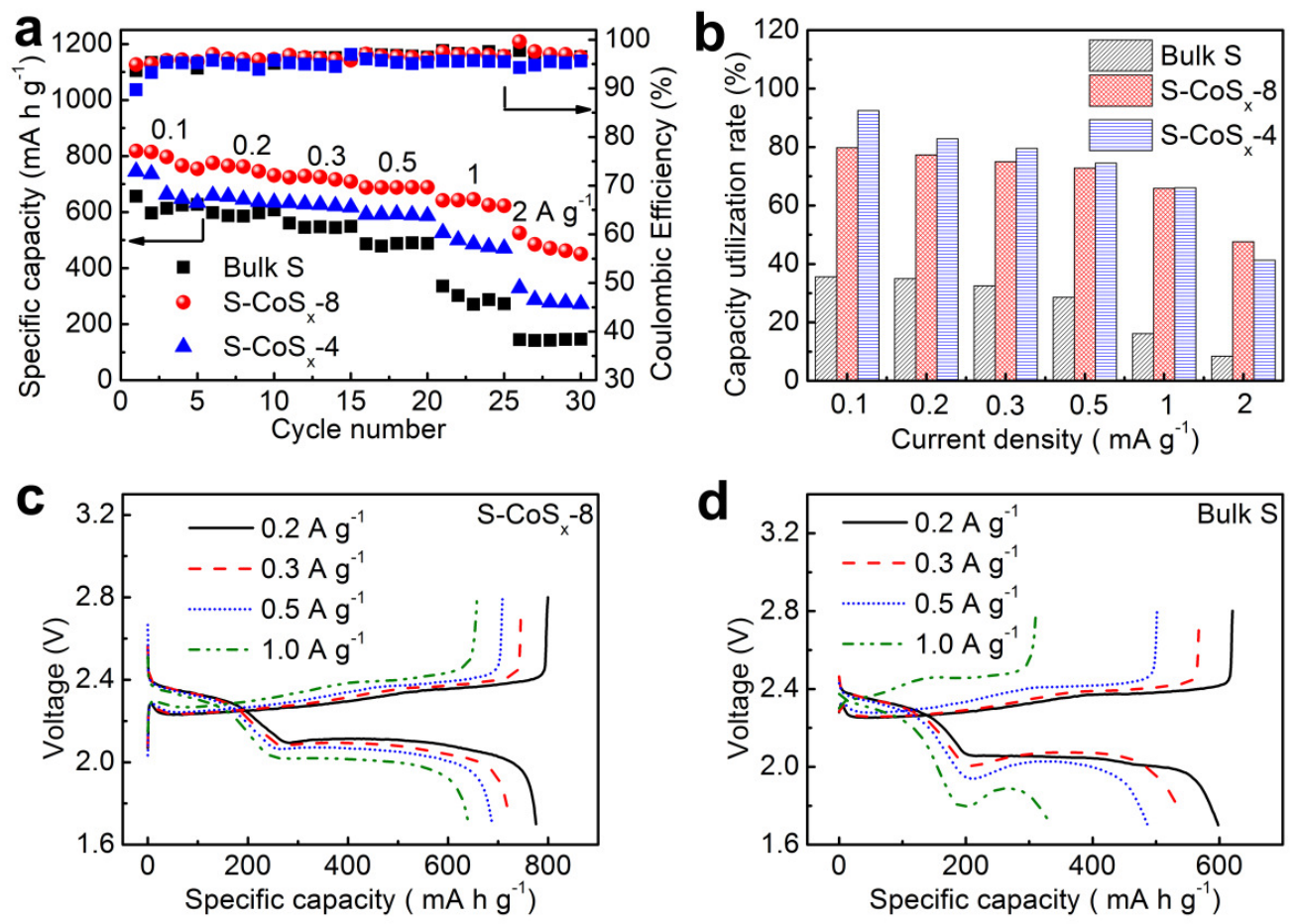

Figure 4. (a) Rate performance and (b) the corresponding capacity utilization rates of $\mathrm{S}-\mathrm{CoS}_{\mathrm{x}}-8$, S-CoS -4 and bulk S, charge-discharge curves of (c) $\mathrm{S}-\mathrm{CoS}_{\mathrm{x}}-8$ nanocomposite and (d) bulk $\mathrm{S}$ at different current densities from 0.2 to $1 \mathrm{~A} \mathrm{~g}^{-1}$.

Electrochemical impedance spectra were conducted to gain detailed understanding of the electrode reaction kinetics. As shown in Figure 5a, the spectra can be fitted according to the inserted equivalent circuit, where $\mathrm{R}_{1}$ represents the ohmic resistance, mainly including the resistances from the electrolyte and electrode, $R_{2}$ is the interphase contact resistance, and $R_{3}$ reflects the charge-transfer resistance. ${ }^{49-50}$ The estimated values of $R_{1}, R_{2}$ and $R_{3}$ are shown in Figure 5b. Clearly, $R_{1}, R_{2}$, and $R_{3}$ of $S-C_{0} S_{x}-8$ and $S-C o S_{x}-4$ are lower than those of $S$. Particularly, as compared with $\mathrm{R}_{1}$ of $\mathrm{S}(39 \Omega), \mathrm{R}_{1}$ of $\mathrm{S}_{-} \mathrm{CoS}_{\mathrm{x}}-8(3.5 \Omega)$ and $\mathrm{S}-\mathrm{CoS}_{\mathrm{x}}-4(5 \Omega)$ are substantially reduced. Considering the cells have unique electrolyte resistance, the variation of $\mathrm{R}_{1}$ is closely associated with the electrode materials. The result reveals that the conductivity of S- 
$\mathrm{CoS}_{\mathrm{x}}-8$ and $\mathrm{S}-\mathrm{CoS}_{\mathrm{x}}-4$ should be greatly improved with the help of conductive cobalt sulfides. Consequently, due to conductivity improvement and presence of sulfur nanoparticles, $\mathrm{S}-\mathrm{CoS}_{\mathrm{x}}-8$ and S-CoS -4 exhibit much lower charge-transfer resistance $\left(\mathrm{R}_{3}\right)$, thereby resulting in faster electrode reaction kinetics.
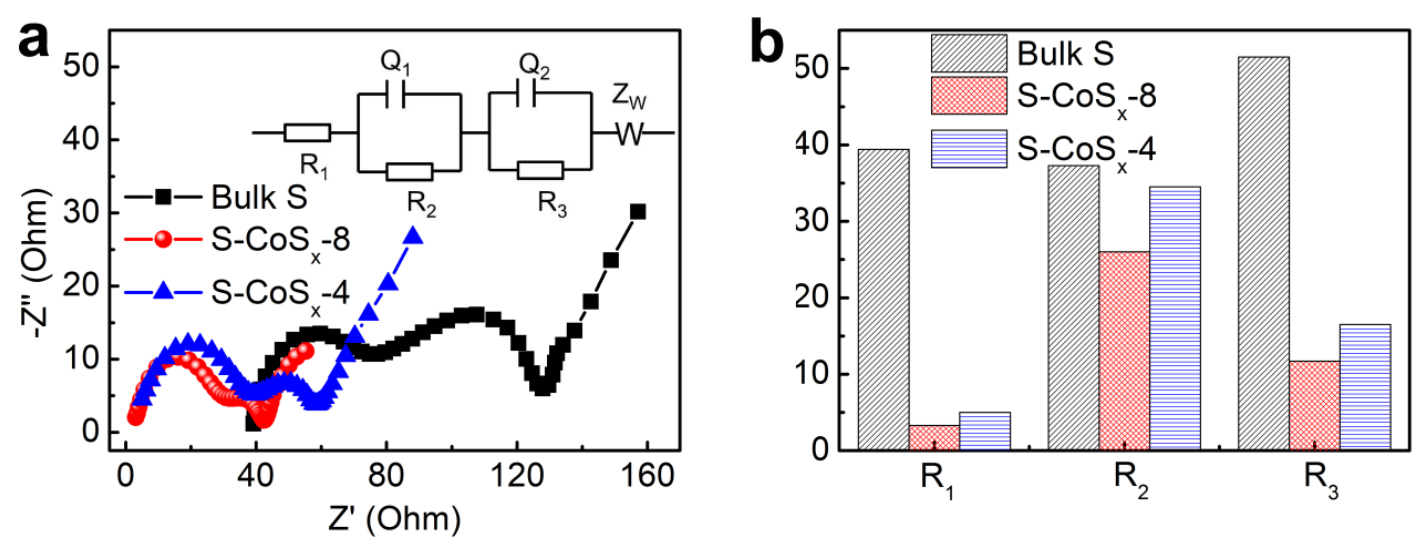

Figure 5. (a) Electrochemical impedance spectra measured at $2.3 \mathrm{~V}$ after two cycles (insert is the equivalent circuit) and (b) resistances of $S-\operatorname{CoS}_{x}-8, S-C_{0} S_{x}-4$ and bulk $S$.

$\mathrm{CV}$ curves of the electrodes measured under different scan rates from 0.1 to $1 \mathrm{mV} \mathrm{s}^{-1}$ were applied to further investigate the electrode reaction kinetics with respect to the lithium ion diffusion coefficient. As shown in Figure 6a-c, two reduction peaks of bulk S merge when the scan rate reaches $0.25 \mathrm{mV} \mathrm{s}^{-1}$, while $\mathrm{S}-\mathrm{CoS}_{\mathrm{x}}-8$ and $\mathrm{S}-\mathrm{CoS}_{\mathrm{x}}-4$ still exhibit two distinct separated cathodic peaks, suggesting their lower polarization than that of pure S. The anodic current peaks of the cathodes have a linear relationship with the square root of scan rate (Figure 6d). Therefore, a classic Randles-Sevcik equation can be used to describe the lithium diffusion process: $\mathrm{I}_{\mathrm{p}}=2.69 \times 10^{5} \mathrm{n}^{3 / 2} \mathrm{AD}^{1 / 2} \mathrm{Cv}^{1 / 2}$, where $\mathrm{I}_{\mathrm{p}}$ is the peak current, $\mathrm{n}$ is the charge transfer number, $\mathrm{A}$ is the geometric area of the active electrode, D is the lithium ion diffusion coefficient, $\mathrm{C}$ is the concentration of $\mathrm{Li}^{+}$in the cathode, and $v$ is the potential scan rate. The slops of the curves 
$\left(\mathrm{I}_{\mathrm{p}} / \mathrm{v}^{1 / 2}\right)$ shown in Figure $6 \mathrm{~d}$ reflect apparent lithium ion diffusion rate, as $\mathrm{n}, \mathrm{A}$ and $\mathrm{C}$ of are supposed to be equal for the three samples. It is obvious that bulk S shows the lowest diffusivity, which mainly arises from the sluggish reaction kinetics and severe shuttle effect of insulating sulfur. In contrast, $\mathrm{S}-\mathrm{CoS}_{\mathrm{x}}-8$ nanocomposite delivers the fastest $\mathrm{Li}^{+}$diffusion coefficient, followed by $\mathrm{S}-\mathrm{CoS}_{\mathrm{x}}-4$ nanocomposite, confirming that the introduction of cobalt sulfide nanoparticles enable highly efficient reaction kinetics of the cathodes. The results are in good agreement with the electrochemical impedance results as demonstrated in Figure 5.
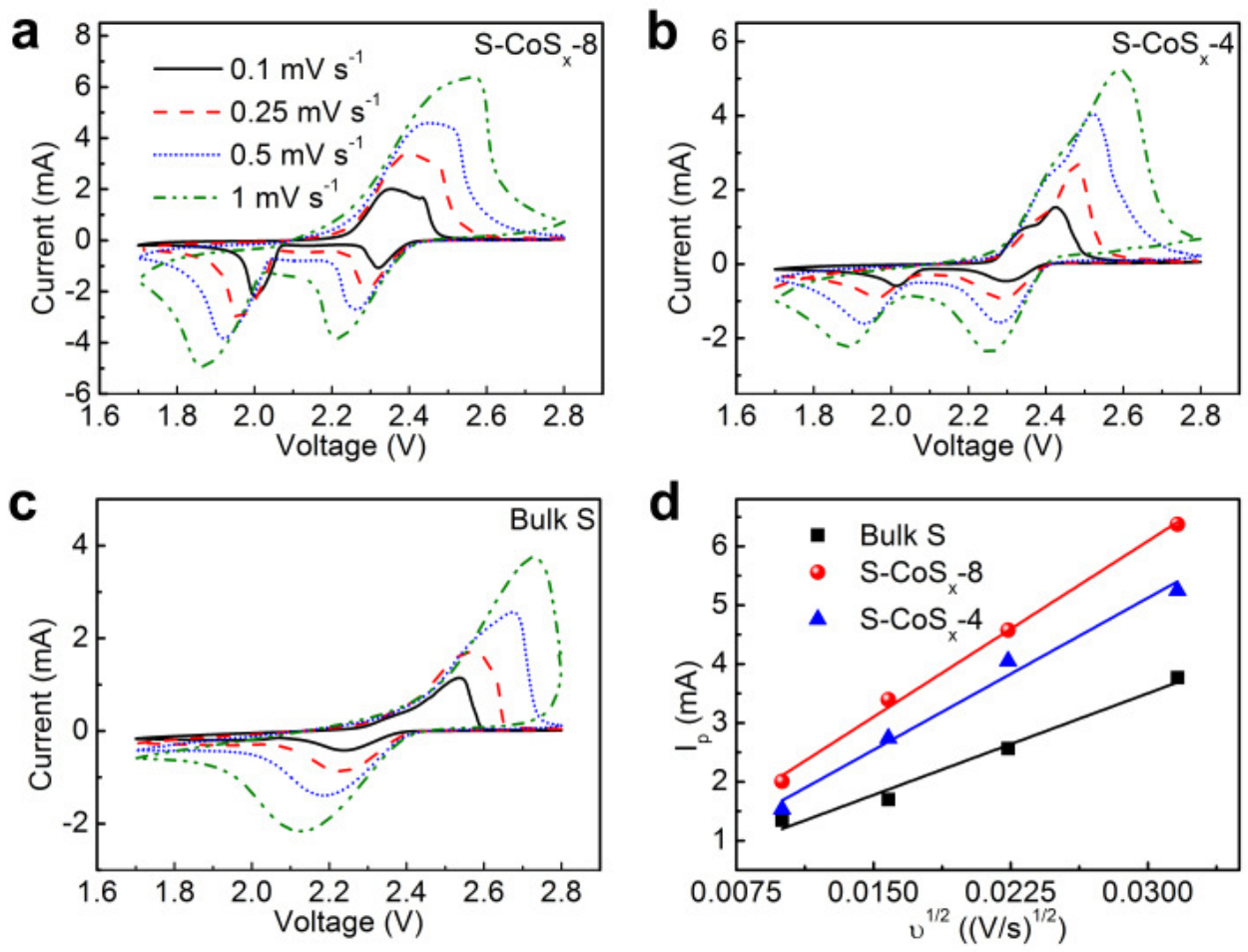

Figure 6. Typical CV profiles of (a) $S-C_{0} S_{x}-8$, (b) $S-C_{0} S_{x}-4$, and (c) bulk $S$ at different scan rates from 0.1 to $1 \mathrm{mV} \mathrm{s}^{-1}$, and (d) plots of anodic peak current vs square root of the scan rate.

Although the sulfur-cobalt sulfide nanocomposites show substantially enhanced reaction kinetics, the cycling performance of the nanocomposites still remains a challenge and improve a 
little bit compared to bulk S (Figure S9, Supporting Information). The capacity retention is around 423.4 and $353.5 \mathrm{~mA} \mathrm{~h} \mathrm{~g}^{-1}$ after 100 cycles at $100 \mathrm{~mA} \mathrm{~g}$ for $\mathrm{S}-\mathrm{CoS}_{\mathrm{x}}-8$ and $\mathrm{S}-\mathrm{CoS}_{\mathrm{x}}-4$, respectively. In contrast, bulk S delivers a lower retention capacity of $269 \mathrm{~mA} \mathrm{~h} \mathrm{~g}^{-1}$ after 100 cycles. S-CoS -8 and $\mathrm{S}-\mathrm{CoS}_{\mathrm{x}}-4$ exhibit the Coulombic efficiency of $96.7 \%$ and $96.6 \%$, respectively, while bulk sulfur shows a lower efficiency of $94 \%$ after 100 cycles. The results suggest that the incorporation of cobalt sulfides does not trap lithium polysulfides as efficiently as reported previously, ${ }^{12-13}$ and the shuttle effect that mainly accounts for capacity fading is not effectively mitigated. One possible reason is that, cobalt sulfide nanograins are uniformly distributed in the sulfur-based matrix, which isolates cobalt sulfide nanograins from the electrolyte, thereby reducing the adsorption of polysulfides. On the other hand, the electrodes discussed in this work only contains $10 \mathrm{wt} \%$ conductive additive; in contrast, many previously reported electrodes contain more conductive additives, even as high as $40 \mathrm{wt} \%$, which is also beneficial for achieving better cycling performance besides rate capability. Specific effort is required to develop efficient approaches to eventually improve the cycling performance of this new cathode material, and we believe that the capacity retention can be further enhanced by combining some well-developed strategies for cycling improvement.

\section{CONCLUSIONS}

In summary, a facile and scalable one-pot method was developed to synthesize sulfur-cobalt sulfide nanocomposites. Sulfur and cobalt sulfide nanoparticles are distributed homogeneously in the nanocomposites. Electrochemical characterizations reveal that the sulfur-cobalt sulfide nanocomposites demonstrate higher specific capacity, and significantly improved rate capability than those for bulk $\mathrm{S}$ cathode. The enhanced performance is mainly attributed to the introduction 
of conductive cobalt sulphide nanoparticles and the presence of $S$ nanoparticles, both of which are of great significance to help accelerate electrode reaction kinetics.

\section{ASSOCIATED CONTENT}

\section{Supporting Information}

The Supporting Information is available free of charge.

Figures and images as detailed in the text.

\section{AUTHOR INFORMATION}

\section{Corresponding Author}

* E-mail address: wenping@uow.edu.au (W. Sun)

\section{Notes}

The authors declare no competing financial interest.

\section{ACKNOWLEDGMENT}

This work was financially supported by Australian Research Council (ARC) DECRA Grant (DE160100596).

\section{REFERENCES}

1. Manthiram, A.; Chung, S. H.; Zu, C. Lithium-sulfur batteries: progress and prospects. Adv. Mater. 2015, 27, 1980.

2. Evers, S.; Nazar, L. F. New Approaches for High Energy Density Lithium-sulfur Battery Cathodes. Acc. Chem. Res. 2013, 45, 1135.

3. Fang, X.; Peng, H. A revolution in electrodes: recent progress in rechargeable lithium-sulfur batteries. Small 2015, 11, 1488.

4. Qie, L.; Zu, C.; Manthiram, A. A High Energy Lithium-Sulfur Battery with Ultrahigh-Loading Lithium Polysulfide Cathode and its Failure Mechanism. Adv. Energy Mater. 2016, 6, 1502459. 
5. Cao, J.; Chen, C.; Zhao, Q.; Zhang, N.; Lu, Q.; Wang, X.; Niu, Z.; Chen, J. A Flexible Nanostructured Paper of a Reduced Graphene Oxide-Sulfur Composite for High-Performance Lithium-Sulfur Batteries with Unconventional Configurations. Adv. Mater. 2016, 28, 9629.

6. Fei, L.; Li, X.; Bi, W.; Zhuo, Z.; Wei, W.; Sun, L.; Lu, W.; Wu, X.; Xie, K.; Wu, C.; Chan, H. L.; Wang, Y. Graphene/sulfur hybrid nanosheets from a space-confined "sauna" reaction for high-performance lithium-sulfur batteries. Adv. Mater. 2015, 27, 5936.

7. Hu, G.; Xu, C.; Sun, Z.; Wang, S.; Cheng, H. M.; Li, F.; Ren, W. 3D Graphene-FoamReduced-Graphene-Oxide Hybrid Nested Hierarchical Networks for High-Performance Li-S Batteries. Adv. Mater. 2016, 28, 1603.

8. Qie, L.; Manthiram, A. A facile layer-by-layer approach for high-areal-capacity sulfur cathodes. Adv. Mater. 2015, 27, 1694.

9. Ding, Y.; Kopold, P.; Hahn, K.; van Aken, P. A.; Maier, J.; Yu, Y. Facile Solid-State Growth of 3D Well-Interconnected Nitrogen-Rich Carbon Nanotube-Graphene Hybrid Architectures for Lithium-Sulfur Batteries. Adv. Funct. Mater. 2016, 26, 1112.

10. Ye, C.; Zhang, L.; Guo, C.; Li, D.; Vasileff, A.; Wang, H.; Qiao, S. A 3D Hybrid of Chemically Coupled Nickel Sulfide and Hollow Carbon Spheres for High Performance LithiumSulfur Batteries. Adv. Funct. Mater. 2017, 27, 1702524.

11. Wu, C.; Fu, L.; Maier, J.; Yu, Y. Free-standing graphene-based porous carbon films with three-dimensional hierarchical architecture for advanced flexible Li-sulfur batteries. J. Mater. Chem. A 2015, 3, 9438.

12. Yuan, Z.; Peng, H. J.; Hou, T. Z.; Huang, J. Q.; Chen, C. M.; Wang, D. W.; Cheng, X. B.; Wei, F.; Zhang, Q. Powering Lithium-Sulfur Battery Performance by Propelling Polysulfide Redox at Sulfiphilic Hosts. Nano Lett. 2016, 16, 519.

13. Zhou, G.; Tian, H.; Jin, Y.; Tao, X.; Liu, B.; Zhang, R.; Seh, Z. W.; Zhuo, D.; Liu, Y.; Sun, J.; Zhao, J.; Zu, C.; Wu, D. S.; Zhang, Q.; Cui, Y. Catalytic oxidation of $\mathrm{Li}_{2} \mathrm{~S}$ on the surface of metal sulfide for Li-S batteries. PNAS 2017, 114, 840.

14. Li, Z.; Zhang, J.; Guan, B.; Wang, D.; Liu, L. M.; Lou, X. W. A sulfur host based on titanium monoxide@carbon hollow spheres for advanced lithium-sulfur batteries. Nat. Commun. 2016, 7, 13065.

15. He, X.; Hou, H.; Yuan, X.; Huang, L.; Hu, J.; Liu, B.; Xu, J.; Xie, J.; Yang, J.; Liang, S.; $\mathrm{Wu}, \mathrm{X}$. Electrocatalytic activity of lithium polysulfides adsorbed into porous $\mathrm{TiO}_{2}$ coated MWCNTs hybrid structure for lithium-sulfur batteries. Sci. Rep. 2017, 7, 40679.

16. Tao, X.; Wang, J.; Liu, C.; Wang, H.; Yao, H.; Zheng, G.; Seh, Z. W.; Cai, Q.; Li, W.; Zhou, G.; Zu, C.; Cui, Y. Balancing surface adsorption and diffusion of lithium-polysulfides on nonconductive oxides for lithium-sulfur battery design. Nat. Commun. 2016, 7, 11203.

17. Liang, X.; Hart, C.; Pang, Q.; Garsuch, A.; Weiss, T.; Nazar, L. F. A highly efficient polysulfide mediator for lithium-sulfur batteries. Nat. Commun. 2015, 6, 5682.

18. Chen, C. Y.; Peng, H. J.; Hou, T. Z.; Zhai, P. Y.; Li, B. Q.; Tang, C.; Zhu, W.; Huang, J. Q.; Zhang, Q. A Quinonoid-Imine-Enriched Nanostructured Polymer Mediator for Lithium-Sulfur Batteries. Adv. Mater. 2017, 29, 1606802.

19. Su, D.; Cortie, M.; Fan, H.; Wang, G. Prussian Blue Nanocubes with an Open Framework Structure Coated with PEDOT as High-Capacity Cathodes for Lithium-Sulfur Batteries. Adv. Mater. 2017, 1700587.

20. Li, W.; Zheng, G.; Yang, Y.; Seh, Z. W.; Liu, N.; Cui, Y. High-performance hollow sulfur nanostructured battery cathode through a scalable, room temperature, one-step, bottom-up approach. PNAS 2013, 110, 7148. 
21. Lu, Y.; Gu, S.; Guo, J.; Rui, K.; Chen, C.; Zhang, S.; Jin, J.; Yang, J.; Wen, Z. Sulfonic Groups Originated Dual-Functional Interlayer for High Performance Lithium-Sulfur Battery. ACS Appl. Mater. Interfaces 2017, 9, 14878.

22. Xiao, Z.; Yang, Z.; Wang, L.; Nie, H.; Zhong, M.; Lai, Q.; Xu, X.; Zhang, L.; Huang, S. A Lightweight $\mathrm{TiO}_{2} /$ Graphene Interlayer, Applied as a Highly Effective Polysulfide Absorbent for Fast, Long-Life Lithium-Sulfur Batteries. Adv. Mater. 2015, 27, 2891.

23. Zhou, G.; Li, L.; Wang, D. W.; Shan, X. Y.; Pei, S.; Li, F.; Cheng, H. M. A flexible sulfurgraphene-polypropylene separator integrated electrode for advanced Li-S batteries. Adv. Mater. 2015, 27, 641.

24. Zhou, T.; Lv, W.; Li, J.; Zhou, G.; Zhao, Y.; Fan, S.; Liu, B.; Li, B.; Kang, F.; Yang, Q. Twinborn $\mathrm{TiO}_{2}$-TiN heterostructures enabling smooth trapping-diffusion-conversion of polysulfides towards ultralong life lithium-sulfur batteries. Energy Environ. Sci. 2017, 10, 1694.

25. Chen, H.; Wang, C.; Dong, W.; Lu, W.; Du, Z.; Chen, L. Monodispersed sulfur nanoparticles for lithium-sulfur batteries with theoretical performance. Nano Lett. 2015, 15, 798.

26. Chen, H.; Dong, W.; Ge, J.; Wang, C.; Wu, X.; Lu, W.; Chen, L. Ultrafine sulfur nanoparticles in conducting polymer shell as cathode materials for high performance lithium/sulfur batteries. Sci. Rep. 2013, 3, 1910.

27. Peng, H. J.; Zhang, G.; Chen, X.; Zhang, Z. W.; Xu, W. T.; Huang, J. Q.; Zhang, Q. Enhanced Electrochemical Kinetics on Conductive Polar Mediators for Lithium-Sulfur Batteries. Angew. Chem. Int. Ed. 2016, 55, 12990.

28. Jeong, T.; Choi, D. S.; Song, H.; Choi, J.; Park, S.; Oh, S. H.; Kim, H.; Jung, Y.; Kim, Y. Heterogeneous Catalysis for Lithium-Sulfur Batteries: Enhanced Rate Performance by Promoting Polysulfide Fragmentations. ACS Energy Lett. 2017, 2, 327.

29. Liang, J.; Yin, L.; Tang, X.; Yang, H.; Yan, W.; Song, L.; Cheng, H. M.; Li, F. Kinetically Enhanced Electrochemical Redox of Polysulfides on Polymeric Carbon Nitrides for Improved Lithium-Sulfur Batteries. ACS Appl Mater Interfaces 2016, 8, 25193.

30. Xu, H.; Manthiram, A. Hollow cobalt sulfide polyhedra-enabled long-life, high arealcapacity lithium-sulfur batteries. Nano Energy 2017, 33, 124.

31. Kumar, N.; Raman, N.; Sundaresan, A. Synthesis and Properties of Cobalt Sulfide Phases: $\mathrm{CoS}_{2}$ and $\mathrm{Cog}_{9} \mathrm{~S}_{8}$. Z. Anorg. Allg. Chem. 2014, 640, 1069.

32. Faber, M. S.; Dziedzic, R.; Lukowski, M. A.; Kaiser, N. S.; Ding, Q.; Jin, S. Highperformance electrocatalysis using metallic cobalt pyrite $\left(\mathrm{CoS}_{2}\right)$ micro- and nanostructures. $J$. Am. Chem. Soc. 2014, 136, 10053.

33. Faber, M. S.; Park, K.; Caban-Acevedo, M.; Santra, P. K.; Jin, S. Earth-Abundant Cobalt Pyrite $\left(\mathrm{CoS}_{2}\right)$ Thin Film on Glass as a Robust, High-Performance Counter Electrode for Quantum Dot-Sensitized Solar Cells. J. Phys. Chem. Lett. 2013, 4, 1843.

34. Helen, M.; Reddy, M. A.; Diemant, T.; Golla-Schindler, U.; Behm, R. J.; Kaiser, U.; Fichtner, M. Single step transformation of sulphur to $\mathrm{Li}_{2} \mathrm{~S}_{2} / \mathrm{Li}_{2} \mathrm{~S}$ in Li-S batteries. Sci. Rep. 2015, 5,12146 .

35. Jung, Y.; Kang, B. Understanding abnormal potential behaviors at the 1 st charge in $\mathrm{Li}_{2} \mathrm{~S}$ cathode material for rechargeable Li-S batteries. Phys. Chem. Chem. Phys. 2016, 18, 21500.

36. Peng, S.; Li, L.; Mhaisalkar, S. G.; Srinivasan, M.; Ramakrishna, S.; Yan, Q. Hollow nanospheres constructed by $\mathrm{CoS}_{2}$ nanosheets with a nitrogen-doped-carbon coating for energystorage and photocatalysis. ChemSusChem 2014, 7, 2212.

37. Su, Y. S.; Fu, Y.; Cochell, T.; Manthiram, A. A strategic approach to recharging lithiumsulphur batteries for long cycle life. Nat. Commun. 2013, 4, 2985. 
38. Meng, X.; Deng, J.; Zhu, J.; Bi, H.; Kan, E.; Wang, X. Cobalt Sulfide/Graphene Composite Hydrogel as Electrode for High-Performance Pseudocapacitors. Sci. Rep. 2016, 6, 21717.

39. Bikkarolla, S. K.; Papakonstantinou, $\mathrm{P} . \mathrm{CuCo}_{2} \mathrm{O}_{4}$ nanoparticles on nitrogenated graphene as highly efficient oxygen evolution catalyst. J. Power Sources 2015, 281, 243.

40. Zhao, X.; Jiang, J.; Xue, Z.; Yan, C.; Mu, T. An ambient temperature, $\mathrm{CO}_{2}$-assisted solution processing of amorphous cobalt sulfide in a thiol/amine based quasi-ionic liquid for oxygen evolution catalysis. Chem. Commun. 2017, 53, 9418.

41. Chen, Y.; Zhao, S.; Liu, Z. Influence of the synergistic effect between Co-N-C and ceria on the catalytic performance for selective oxidation of ethylbenzene. Phys. Chem. Chem. Phys. 2015, 17, 14012.

42. Ding, R.; Qi, L.; Jia, M.; Wang, H. Facile synthesis of mesoporous spinel $\mathrm{NiCo}_{2} \mathrm{O}_{4}$ nanostructures as highly efficient electrocatalysts for urea electro-oxidation. Nanoscale 2014, 6 , 1369.

43. Zhu, H.; Zhang, J.; Yanzhang, R.; Du, M.; Wang, Q.; Gao, G.; Wu, J.; Wu, G.; Zhang, M.; Liu, B.; Yao, J.; Zhang, X. When cubic cobalt sulfide meets layered molybdenum disulfide: a core-shell system toward synergetic electrocatalytic water splitting. Adv. Mater. 2015, 27, 4752.

44. Fantauzzi, M.; Elsener, B.; Atzei, D.; Rigoldi, A.; Rossi, A. Exploiting XPS for the identification of sulfides and polysulfides. RSC Adv. 2015, 5, 75953.

45. Tao, X.; Chen, F.; Xia, Y.; Huang, H.; Gan, Y.; Chen, X.; Zhang, W. Decoration of sulfur with porous metal nanostructures: an alternative strategy for improving the cyclability of sulfur cathode materials for advanced lithium-sulfur batteries. Chem. Commun. 2013, 49, 4513.

46. Zhang, K.; Xu, Y.; Lu, Y.; Zhu, Y.; Qian, Y.; Wang, D.; Zhou, J.; Lin, N.; Qian, Y. A graphene oxide-wrapped bipyramidal sulfur@polyaniline core-shell structure as a cathode for Li$\mathrm{S}$ batteries with enhanced electrochemical performance. J. Mater. Chem. A 2016, 4, 6404.

47. Wang, Q.; Jiao, L.; Han, Y.; Du, H.; Peng, W.; Huan, Q.; Song, D.; Si, Y.; Wang, Y.; Yuan, H. $\mathrm{CoS}_{2}$ Hollow Spheres: Fabrication and Their Application in Lithium-Ion Batteries. J. Phys. Chem. C 2011, 115, 8300 .

48. Huang, G.; Chen, T.; Wang, Z.; Chang, K.; Chen, W. Synthesis and electrochemical performances of cobalt sulfides/graphene nanocomposite as anode material of Li-ion battery. $J$. Power Sources 2013, 235, 122.

49. Zeng, J.; Wang, S.; Liu, Q.; Lei, X. High-capacity V-/Sc-/Ti-doped $\mathrm{MnO}_{2}$ for $\mathrm{Li} / \mathrm{MnO}_{2}$ batteries and structural changes at different discharge depths. Electrochim. Acta 2014, 127, 115.

50. Deng, Z.; Zhang, Z.; Lai, Y.; Liu, J.; Li, J.; Liu, Y. Electrochemical Impedance Spectroscopy Study of a Lithium/Sulfur Battery: Modeling and Analysis of Capacity Fading. J. Electrochem. Soc. 2013, 160, A553. 
Table of Contents

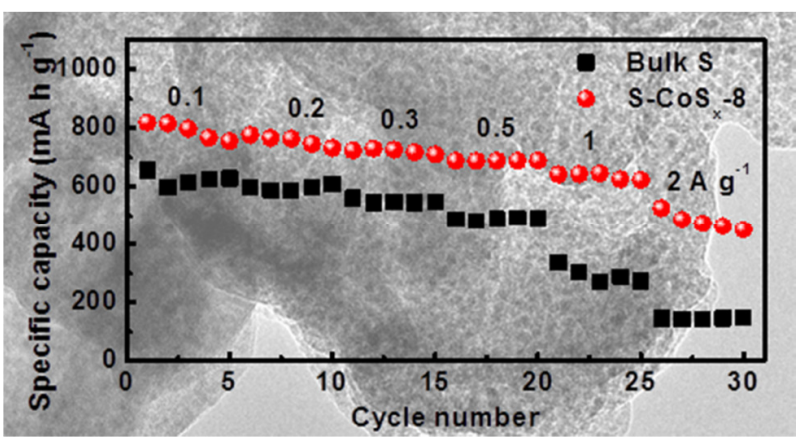

